\title{
Microfabrication of Ceramics based on Colloidal Suspensions and Photoresist Masks
}

\author{
Martin Heule, Ludwig J. Gauckler \\ Institute of Nonmetallic Inorganic Materials, Department of Materials \\ ETH Swiss Federal Institute of Technology \\ 5 Sonneggstrasse, $\mathrm{CH}-8092$ Zurich, Switzerland \\ heule@nonmet.mat.ethz.ch
}

\begin{abstract}
Thick film ceramic microstructures with cross sectional areas of 5 by $10 \mu \mathrm{m}^{2}$ were fabricated by casting aqueous colloidal suspensions of fine ceramic powders into photoresist structures. In order to anneal the ceramic microstructures without damaging, the dissolving behaviour of novolak resist was empirically assessed for different solvents. As a result, the resist was dissolved in tetrahydrofurane before pyrolysis. The processing of ceramic powders in the form of suspensions as used for bulk ceramic parts is new to the field of microfabrication.
\end{abstract}

Keywords: microfabrication of ceramics, ceramic powders, colloidal suspension, photoresist casting

\section{Introduction}

Ceramic materials in electronics and microelectromechanical systems (MEMS) find extensive use as insulating layers, coatings or as dielectric layers in capacitor designs for dynamic random access memories (DRAM) [1]. Practically all of these are deposited by various thin film techniques such as chemical and physical vapour deposition, sol-gel or other coating technologies. The use of ceramic powders for generating microstructured ceramic elements is new in the field of MEMS devices. For instance, micromachined gas sensors with a tin oxide thick-film layer deposited as colloidal suspension have been reported $[2,3]$. The deposition methods predominantly in use with thick film ceramics are different drop coating methods and screen printing. It is virtually impossible to control the geometry of drop coated layers on the low micrometer level, whereas the practical resolution limits of screen printing lie in the range of $0.1 \mathrm{~mm}$. We have recently introduced novel microfabrication techniques using standard powder-based ceramic suspensions for generating features in the low micrometer range [4-6]. Promising results were obtained also by using Soft Lithography $[7,8]$. In this paper we report on a practical application based on the filling of photoresist structures by casting of colloidal suspensions. Except for standard equipment to perform photolithography, the methods presented neither require vacuum technology nor other expensive devices and can be carried out in a general laboratory. Ceramic microlines of tin oxide with a cross sectional area of approx. 5 by $10 \mu \mathrm{m}^{2}$ were produced. The dissolution behaviour of the novolak/diazochinone photoresist material has been characterized empirically also for solvents not common in standard photolithography processing steps.

\section{Experimental}

Photoresist structures for casting: a thick film novolak/diazochinone based positive photoresist (AZ4562, Clariant GmbH, Wiesbaden, Germany) was spun at $3500 \mathrm{rpm}$ (thickness of $6 \mu \mathrm{m}$ ) onto silicon test wafers. Prebake was performed at $100^{\circ} \mathrm{C}$ for $30 \mathrm{~min}$. Using a Suss MA- 6 aligner, line patterns featuring line widths of $10 \mu \mathrm{m}$ were transferred by UV illumination through a chrome mask and developed with Microposit 351 basic solution (Shipley Inc., Marlborough, MA, USA). Before casting the ceramic microstructures, the 
open silicon surfaces of the pits were surfaceactivated by 2 min of oxygen plasma treatment.

Tin oxide suspension: pure tin oxide powder with a grain size of $d_{50}=277 \mathrm{~nm}$ as determined by a Microtrac UPA 150 particle sizer was used as received (Cerac Inc., Milwaukee, WI, USA). Polyacrylic acid sodium salt 5100 (1.84 g, Fluka AG, Buchs, Switzerland) was dissolved in water $(6.65 \mathrm{~g}$, Millipore $18 \mathrm{M} \Omega \mathrm{cm}$ ) and $0.06 \mathrm{~g}$ ammonia $\left(25 \%\right.$ in $\mathrm{H}_{2} \mathrm{O}$ ) were added, rising the $\mathrm{pH}$ from 7.4 to 9.9 . The solution was filtered through a $200 \mathrm{~nm}$ pore size teflon filter and subsequently used as additive. Tin oxide powder $(21.1 \mathrm{~g})$ was then slowly dispersed in $6.01 \mathrm{~g}$ of water containing 150 $\mu l$ of additive solution. The admixture was frequently interrupted by ball milling steps using zirconia balls.

Dissolution tests: all solvents were of analytical grade and used as received. Some samples from photolithography were used without further treatment, others were postbaked at $120^{\circ} \mathrm{C} / 30 \mathrm{~min}$ resp. $150^{\circ} \mathrm{C} / 30 \mathrm{~min}$ (see Table 1). Dissolution times were assessed by immersing wafer pieces of approx. 5 by $8 \mathrm{~mm}^{2}$ with developed and well visible resist structures in 12 $\mathrm{ml}$ of solvent. Time was recorded after the observation of complete disappearance of all structural features. After $24 \mathrm{hrs}$, the undissolved resist samples were dried for $12 \mathrm{hrs}$ at $60^{\circ} \mathrm{C}$ and inspected.

\section{Results and Discussion}

The fabrication process is schematically summarized in Figure 1. Crucial to the whole process was the ability to induce different wetting properties of the materials involved. Since the tin oxide suspension is based on water, its contact angle on the photoresist layer was determined to be $89^{\circ}$. Using a cut elastomeric blade of polydimethylsiloxane (contact angle to water $120^{\circ}$ ), it was possible to drag a droplet of suspension over the substrate without leaving significant powder traces. The recessed line patterns could be filled completely independent of the moving direction of the blade. However, some powder remainders around the pits were always present on a small scale, see Figure 2. In order to remove them, the blade was wetted with water vapour and repeatedly drawn over the substrate until the resist surface was clean. Another important issue was the ceramic processing. In classic ceramics manufacturing, a ceramic suspension is dried after

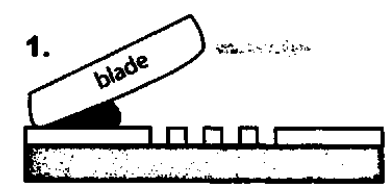

3. PR fixes ceramic green body

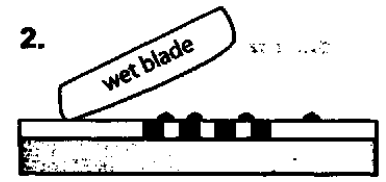

4. pyrolysis of PR, annealing

Figure 1. Schematic of the ceramic microfabrication process. 1) Colloidal suspension of tin oxide is cast into the pits of a $6 \mu \mathrm{m}$ thick structured photoresist (PR) mask using a soft polymer blade. 2) Remainders are wiped by a wetted blade. 3) Mask is dissolved, leaving only a thin resist layer after drying which fixes the ceramic green body. 4) All resist material is pyrolysed and the ceramic microstructures are sintered.

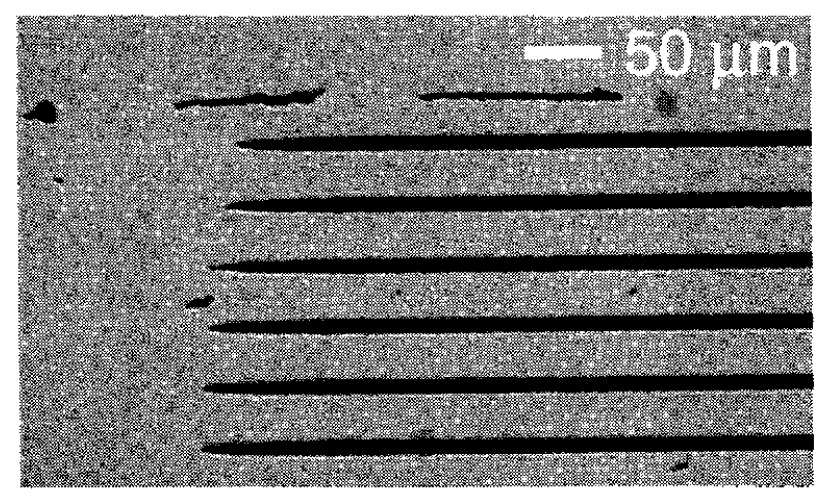

Figure 2. Microscope image of filled line-shaped pits of photoresist (dark, witdth $10 \mu \mathrm{m}$ ) before removal of powder traces atop.

casting into shape, forming a so-called green body [9]. Green bodies consist of highly porous, nonconsolidated networks of powder and are therefore fragile. Higher density and characteristic ceramic properties are then reached by sintering at high temperatures. Polymeric binders usually are added to enhance the mechanical strength of green bodies. In our case the polyacrylic acid served as a weak binding agent in the dry state. In earlier thermogravimetry experiments it was found that AZ4562 photoresist pyrolyses between $400^{\circ} \mathrm{C}$ and $500^{\circ} \mathrm{C}$. However, the microstructures could not be sintered directly because of thermal expansion of the resist. Before pyrolysis it exerted too much pressure on the green microstructures and destroyed them. In order to find a suitable solvent 
Table 1. Empirically observed dissolution behaviour of $6 \mu \mathrm{m}$ thick AZ4562 photoresist structures upon immersion in commonly used organic solvents. Prebake was performed at $100^{\circ} \mathrm{C} / 30 \mathrm{~min}$ for all samples, some were postbaked at $120^{\circ} \mathrm{C} / 30 \mathrm{~min}$ or $150^{\circ} \mathrm{Cl} 30 \mathrm{~min}$ respectively.

\begin{tabular}{lrrrr}
\hline \multirow{2}{*}{ Solvent } & \multicolumn{4}{c}{ Polarity dissolving time /sec } \\
& $\mathrm{E}_{\mathrm{T}}^{\mathrm{N}}$ & $\begin{array}{r}100^{\circ} \mathrm{C} \\
\text { prebake }\end{array}$ & $\begin{array}{r}120^{\circ} \mathrm{C} \\
\text { postb. }\end{array}$ & $\begin{array}{r}150^{\circ} \mathrm{C} \\
\text { postb. }\end{array}$ \\
\hline Water & 1.000 & $-^{\mathrm{b}}$ & - & - \\
Acetone & 0.355 & $0-3$ & $0-3$ & $0-3$ \\
Ethyl acetate & 0.228 & $0-3$ & $10-15$ & $10-15$ \\
Tetrahydrofuran & 0.207 & $10-15$ & $10-15$ & $10-15$ \\
Toluene & 0.099 & - & - & - \\
n-Hexane & 0.009 & - & - & - \\
\end{tabular}

a Solvents are ordered according to polarity as determined by the solvatochromic effect on the $\pi-\pi^{*}$ transition energy observed in UV/VIS spectroscopy of pyridinium-N-phenoxide betaine dye [10]. Normalised values are given. ${ }^{\text {b }}$ - denotes: insoluble during $24 \mathrm{hrs}$.

that dissolves the resist without damaging the fragile ceramics by liberating tin oxide particles, a series of empirical dissolution tests was run. The results are shown in Table 1 . Only solvents of intermediate polarity are able to dissolve AZ4562 quickly. Highly polar solvents as water and apolar solvents as toluene and hexane fail. By postbaking the samples, i.e. cross-linking the novolak, a reduction in solubility could be expected. For the postbake temperatures investigated, the effect was found to be of minimal influence.

All these findings are consistent with the chemical structure of Novolak/diazochinone resists [11]. For the third step (Figure 1) therefore, tetrahydrofurane was chosen, the solvent with the largest polarity difference to water that still dissolves the resist.

After gently dipping the substrate filled with ceramic green body into tetrahydrofurane for $30 \mathrm{~s}$, the sample was allowed to dry. A very thin resist coating remained, covering the whole surface including the ceramics. This layer then provided some additional fixation during the early stages of the pyrolysis/sintering process which was carried out by heating slowly to pyrolysis temperature $\left(500^{\circ} \mathrm{C}\right)$ followed by raising the temperature to the sintering step $\left(800^{\circ} \mathrm{Cl} 5 \mathrm{hrs}\right)$. Subsequently, the resulting ceramic microlines were cleaned of loose powder remains by rinsing with water and by treating in a weak ultrasonic bath.

SEM images of the resulting structures are shown in Figure 3. These microstructures exhibit significant differences to structured thin film ceramics: First, the aspect ratio lies in the range of one without the disadvantage of long deposition times in thin film technology. Secondly, such powder-based ceramic microstructures may retain a certain degree of porosity and thus a high specific surface area, a feature previously unfamiliar to MEMS sytems. Thirdly, the powder
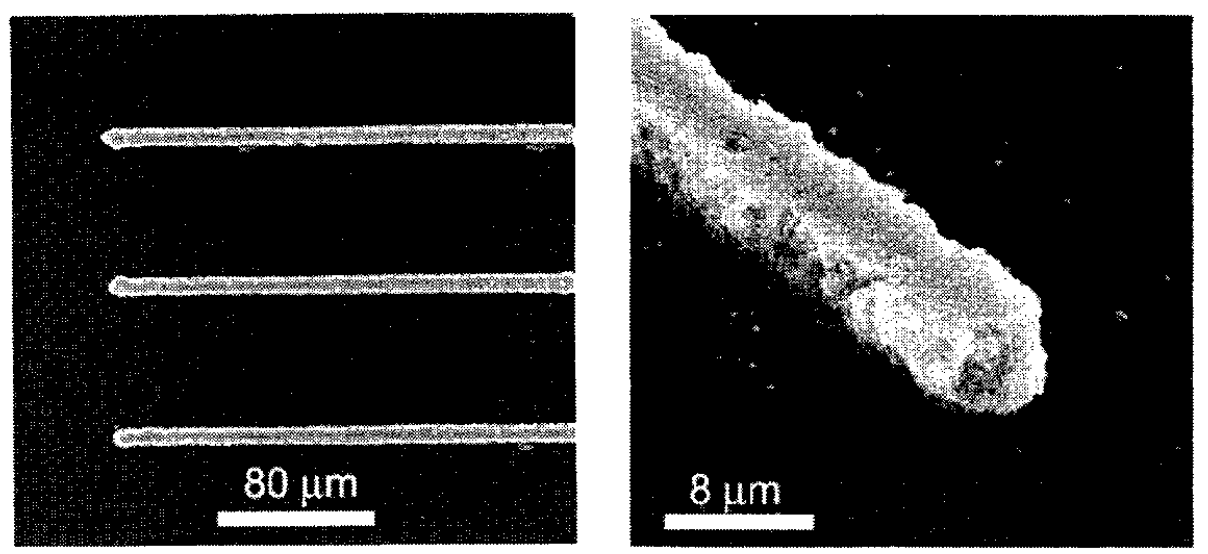

Figure 3. SEM images of sintered ceramic microlines. Left, a view from top is given. Right, a close-up view of a line end seen from a tilting angle of $45^{\circ}$. The three-dimensional shape of the line, which is approx. $5 \mu \mathrm{m}$ high and $10 \mu \mathrm{m}$ in width, is evident. 
synthesis and processing are separated. Therefore, a powder with well defined micro-, nano- and crystal structure or exactly tuned stoichiometry may be prepared and then used in microfabrication.

\section{Summary}

Ceramic microstructures of $10 \mu \mathrm{m}$ size were successfully fabricated using casting of tinoxide powder suspension into photolithographically defined novolak/ diazochinone resist structures. The use of ceramic powders and the abundant experience available in powder synthesis probably will provide MEMS systems with new capabilities that are based on functional ceramics, with catalytic activity, controlled porosity, pyroelectricity, biocompatibility and others. Future experiments will focus on compatibility issues to other microfabrication methods and MEMS systems.

\section{Acknowledgements.}

The authors would like to thank Prof. Dr. J. Dual and Dr. S. Blunier (Institute of Mechanical Systems IMES, ETHZ) for generously providing access to photolithography equipment. Financial support for this study was received from Swiss CTI “Top Nano 21" Project.

\section{References.}

1. O. Auciello, R. Ramesh, MRS Bulletin, 21, (1996), 7, 29.

2. D. Briand, A. Krauss, B. van der Schoot, U. Weimar, N. Barsan, W. Gopel, N. F. de Rooij, Sens. Actuator B-Chem., 68, (2000), 1-3, 223233.

3. H. L. Tuller, J. Electroceram., 4, (2000), 2, 415-425.

4. U. Schönholzer, R. Hummel, L. J. Gauckler, Adv. Mater., 12, (2000), 17, 1261-1263.

5. U. Schönholzer, L. J. Gauckler, Adv. Mater., 11, (1999), 8, 630-632.

6. U. P. Schönholzer, Microfabrication of Ceramics; ETH Zurich, 1999, (PhD thesis)

7. Y. Xia, G. M. Whitesides, Angew. Chem. Int. Ed., 37, (1998), 550-575.

8. M. Heule, L. Meier, L. J. Gauckler, Mat. Res. Soc. Symp., (2000), Vol. 657, EE9.4.

9. J. S. Reed, Principles of Ceramics Processing (Second Edition); Wiley, New York, 1995, p. $33 \mathrm{ff}$.

10. C. Reichardt, Solvents and Solvent Effects in Organic Chemistry; VCH: Weinheim, 1988, 359.

11. A. Reiser, H. Y. Shih, T. F. Yeh, J. P. Huang, Angew. Chem. Int. Ed., 35, (1996), 2428-2440. 